\title{
Professor Charles D Meigs (1792-1869) of Philadelphia and persistent fetal circulation
}

\author{
Peter M Dunn
}

Charles Delucena Meigs was born in Bermuda in 1792 . In 1799 the family moved from New Haven to Athens, Georgia, when his father was appointed president of the college there. Charles graduated in classics at the University of Georgia in 1809. His health was delicate so he then took a year off learning to ride and shoot with the Indians in Cherokee country. Next he studied medicine in Augusta, Georgia, graduating at the University of Philadelphia in 1815. Turning to midwifery in the $1820 \mathrm{~s}$, Meigs translated Velpeau's famous obstetric treatise from the French in 1831 and later published his own Philadelphia Practice of Midwifery in 1838. When the famous Dr Dewees resigned his Chair of Midwifery in the University of Philadelphia, he applied without success for the post. However, shortly afterwards in 1841 he was appointed Professor of Midwifery in the Jefferson Medical College, a post that he held for 19 years. Meigs had married Miss Mary Montgomery, from which union we are told came numerous issue. Both a son and a grandson followed in his footsteps as distinguished Philadelphia obstetricians and pioneers in infant care.

Meigs was a teacher of great power. He had strong religious convictions and we are told that he had the 'lofty belief that he had become a ministering spirit endowed with almost apostolic powers for those who placed themselves under his care'. ${ }^{1}$ Besides being very hard working, he was a man of pure morals, kind and gentle, who cheerfully made himself available at all hours. Although a tobacco smoker, he strongly opposed the evils of intoxicating liquors which, no doubt, contributed to his aggressive opposition to Simpson's introduction of chloroform anaesthesia into midwifery. As he wrote ${ }^{2}$ :

'.. the best guide of the accoucheur is the reply of the patient to his interrogatory, "Does it hurt you?" The patient's reply, "Yes" or "No" is worth a thousand dogmas and precepts, as to planes and axes, and curves of Carus. I cannot, therefore, deem myself justified in casting away my safest and most trustworthy diagnosis, for the questionable equivalent of 10 minutes, exemption from a pain, which, even in this case, is a physiological pain ... I have found that women, provided they were sustained by cheering counsel and promises and carefully freed from the distressing element of

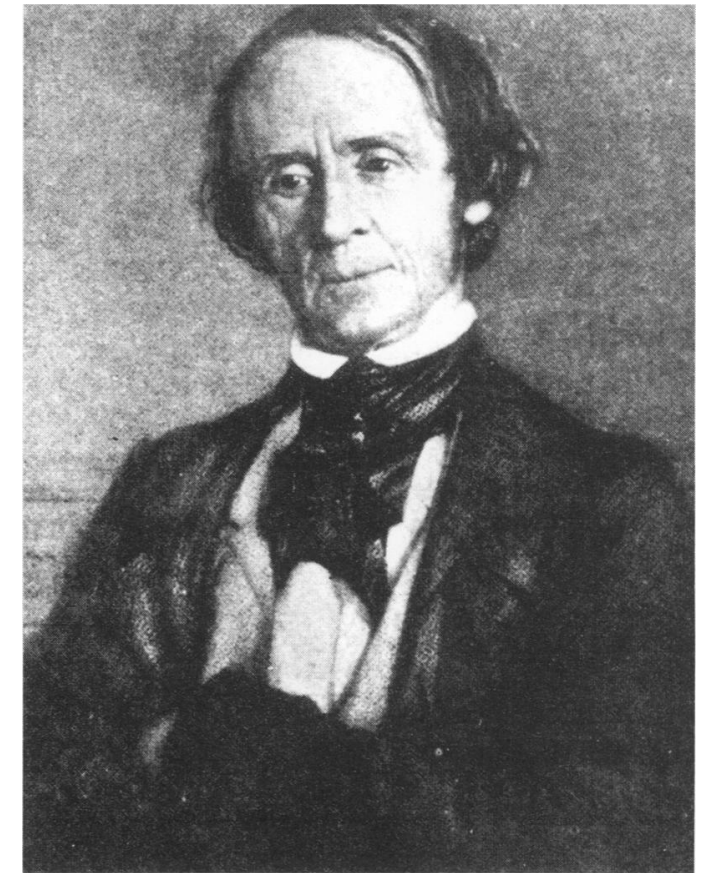

Dr Charles D Meigs (1792-1869).

terror, could, in general, be made to endure without great complaint, these labour pains which the friends of anaesthesia desire so earnestly to abolish and nullify for all the fair daughters of Eve. I cannot bring myself to the conviction that of the two, whether labour-pain or insensibility, insensibility is to be preferred'.

Meigs also summarily dismissed Oliver Wendell-Holmes' suggestion that puerperal fever was contagious. In 1852, he wrote: 'I prefer to attribute these cases to accident or Providence of which I can form a conception than to contagion of which I cannot form any idea'.

Meigs was a prolific writer. Among his publications were contributions on embolism as a sudden cause of postpartum death, on the diseases of the cervix and on child-bed fever. Perhaps, though, his most important texts were Obstetrics: The Science and the Art (1849), ${ }^{2}$ and Observations on Certain of the Diseases of Young Children (1850). ${ }^{3}$ The extract that follows on what Meigs called 'cyanosis neonatorum' but which we would now term persistent fetal circulation is taken from the latter work:

'... Billard, and other observers, have shown that the foramen ovale is open at 
birth, and that it is closed, in the major part of children, by the twentieth or twenty-fifth day; in a vast majority of them, much earlier than this ...

There is a great variety of maladies that interfere with the due aeration of the blood, that a volume rather than a short article, ought to be devoted to their consideration ... My intention is to treat only of those cases that are coincident with permanency, after birth, of the characteristics of the foetal heart ... Many children at birth, or soon after delivery, discharge the blood of the right auricle into the left auricle ...

In November 1832, I had charge of the case of Mrs Taylor ... She was about seven and a half months gone with child ... and became affected with symptoms of premature labor, which at length led to the expulsion of the foetus. The child was alive, but began to turn blue under its respiration. As the cyanotic hue became more intense, the phenomena exhibited by its innervative forces, turned more and more unnatural, so that, employing only faint and imperfect aspirations, often suspended; becoming convulsed, and having feeble, scarcely perceptible pulsations, it seemed at the point of death ... I deemed the state of the child one of partial asphyxia from the mixture of its venous with its arterial blood, the mixture being made by injection through the foramen ovale of the auricular septum. I could devise no treatment upon which to rely for obviating that injection.

I was deeply concerned, and knew not what to do; suddenly I reflected upon the structure of the foetal heart, and the route of the foetal circulation, and I said, if I bring the septum auricularum into a horizontal attitude, will not the blood in the left auricle press the valve of Botalli down upon the foramen ovale and thus save the child, by compelling all the blood of the right auricle to pass by the iter ad ventriculum, and so to the lungs to be aerated?

Having practised midwifery for many years, I had on many occasions witnessed fatal termination of cyanosis neonatorum, both in the premature and the mature child ... whether from too large a foramen ovale or from imperfect development of the respiratory machinery of the lungs by atelectasis.

In the case now under consideration, I placed the child, which seemed nearly dead, upon a pillow, on its right side, the head and trunk being inclined upwards about twenty or thirty degrees. Upon placing it down in this manner, it became quiet - began to breathe more naturally; to acquire a better hue of the face, hands and feet; until, in a very short time, it was quite well again, and did well; having no further returns of the attack of cyanosis neonati ... I thought, and still think, that the child would have died inevitably, but for the treatment ... I still believe that I was the first to invent the treatment ...

Since the date of my first application of this method, I have had numerous occasions to put it in practice, and not a few opportunities of examining the state of the heart after death, in some of which, after vainly applying the treatment, I came to the conclusion that other causes, not patency of the foramen ovale, must exist, to contravene the curative tendency of the method ... I deny not that a constriction of the pulmonary artery may produce cyanosis ... A host, indeed, of accidents and diseases that ruin or disable the respiratory machinery, may produce cyanosis. But of these I have not spoken. I confine my proposition to the persistent use of the foramen ovale after birth, a use in which the blood of the veins takes the course originally followed by that of the placenta. There is no other treatment for cyanosis neonati than that I have suggested; at least, there is no other reasonable treatment ... I am, however, less concerned to witness the acceptation of my rationale, than the adoption of my precept'.

There are many other interesting vignettes to be found in Meigs' writings; for example, he suggests that when superficial stimuli and a warm bath fail to resuscitate a depressed newborn infant then: 'A light electro-galvanic battery, if at hand, might be profitably employed to institute the first contractions of the diaphragm, that are alone required to charge the blood of the pulmonary capillaries with oxygen, which, once in the brain, immediately sets free the hitherto torpid biotic powers of the medulla oblongata'. But he admits that he has had no clinical experience of his own to cite in favour of such a resource.

Meigs resigned his chair in 1860 and retired to his books and his garden in the country. His wife died five years later and he himself passed away in his sleep in 1869 at the age of $77 . \mathrm{He}$ was a man of kindly and disinterested nature, of cultivated intellect and refined taste who deserves to be remembered more for his pioneering interest in fetal and neonatal medicine than for his opposition to the two major obstetric advances of his day.

\footnotetext{
Bell J. Obituary notice of Charles D Meigs, MD. Proceeding of the American Philosophical Society. 1873; 13: 170-9. of the American Philosophical Society. 1873; 13: Philadelphia: Blanchard and Lea, 1849.

3 Meigs CD. Observations on certain of the diseases of young children. Philadelphia: Lea and Blanchard, 1850.
} 